\title{
Effect on Quality of Life in Children and Adolescents with Disabilities after a Functional Intensive Therapy Approach
}

\author{
Buse Busra Sanli ${ }^{1 *}$, YJM Janssen Potten ${ }^{2}$, Ingrid Meeuwsen ${ }^{3}$, Marcel Coenen ${ }^{3}$, Lidia Caponi ${ }^{3}$, Ruud \\ Roijen $^{3}$, Lizette Teeuwen ${ }^{3}$, Gina van den Berge ${ }^{3}$, Coen de Haan ${ }^{3}$, Catherine Steinbusch ${ }^{3}$, Boukje Knops ${ }^{3}$, \\ Cis Knols ${ }^{3}$, Stefan Knoops ${ }^{3}$, Giovanni Paloni ${ }^{4}$ and Eugene AA Rameckers ${ }^{2,3,5,6}$ \\ ${ }^{1}$ Faculty of Physical Therapy and Rehabilitation, Hacettepe University, Turkey \\ ${ }^{2}$ Adelante Center of Expertise in Rehabilitation and Audiology, Valkenburg and Hoensbroek, The Netherlands \\ ${ }^{3}$ Adelante Pediatric Rehabilitation Functional Intensive Therapy Team \\ ${ }^{4}$ Master student, FHML, Maastricht University, the Netherlands \\ ${ }^{5}$ Department of Rehabilitation Medicine, School for Public Health and Primary Care (CAPHRI), Maastricht University, The Netherlands \\ ${ }^{6}$ Rehabilitation Science, Department pediatric rehabilitation, Hasselt University, Belgium
}

Corresponding author: Buse Busra SANLI, Faculty of Physical Therapy and Rehabilitation, Hacettepe University, Turkey

\section{ARTICLE INFO}

Received: 㓞 October 13, 2020

Published: 幽 October 22, 2020

Citation: Buse Busra Sanli, YJM Janssen Potten, Ingrid Meeuwsen, Marcel Coenen, Lidia Caponi, et. al. Effect on Quality of Life in Children and Adolescents with Disabilities after a Functional Intensive Therapy Approach. Biomed J Sci \& Tech Res 31(3)-2020. BJSTR. MS.ID.005091.

Abbreviations: QOL: Quality of Life; H-CIMT: Hybrid-Constrained Induced Movement Therapy; CIMT: Constrained Induced Movement Therapy; BIMT: Bimanual Intensive Movement Therapy; HABIT-ILE: Hand and Arm Bimanual Intensive Therapy Including Lower Extremity; FITCARE4U: Functional Intensive treatment; COPM: Canadian Occupational Performance Measure; SD: Standard Deviation
ABSTRACT

The aim of this study was to determine whether a functional intensive therapy approach can successfully improve the quality of life and ability to perform self-care in children and adolescents with disabilities. Thirty-one children (mean age: 14.13 years, standard deviation: 2.306 years) with disabilities including, but not limited to cerebral palsy, spina bifida, and muscular dystrophy, participated in intensive therapy, which was planned to last fifteen consecutive days. All participants received therapy six hours every day and also participated in home activities and physical and recreational group activities. The primary outcomes included proxy and self-report measurements using KIDSCREEN-52, and the secondary outcomes were determined using the Canadian Occupational Performance Measure (COPM). All assessments were completed by participants and their caregivers both before the intervention and again three months after its completion. Before the intensive therapy, all thirty-one caregivers completed the assessment. After three months, the KIDSCREEN domains of physical well-being (proxy and self-reports; $p=0.01$ ) and school environment (self-report; $p=0.006$ ) had increased significantly, and COPM domains showed a statistically significant increase for all participants $(\mathrm{p}=$ 0.000). Based on the results from the KIDSCREEN and COPM assessments, all participants demonstrated improvements after three months. Therefore, the intensive therapy approach may be an appropriate intervention to improve the quality of life and levels of self-care of children and adolescents with disabilities. However, as there are many aspects that affect QOL, it may be beneficial to include a control group in a future study.

Keywords: Intensive Therapy; Adolescents with Disabilities; Quality of Life; Self-Care

\section{Introduction}

Quality of life (QOL) is a complex, multidimensional, comprehensive concept that includes social, physical, functional,

and mental health [1-3]. In children with disability, QOL has been shown to be diminished, compared to that of their healthy peers [4- 
6], though recently, there has been an increased awareness of the importance of treatment applications to increase QOL in children with disability [7]. There are many factors that affect QOL, such as level of functioning, participation, and psychosocial factors. Conditions that prevent mobility and participation in activities, such as cerebral palsy, spina bifida, and developmental delays, have the same impact on QOL as psychosocial effects [8-10]. Furthermore, motor skills, mental health, and mobility skills contribute to daily and recreational activities, showing a strong correlation to the physical well-being domain of QOL [11]. Thus, in order to improve the QOL and functioning levels of children with disability, goaloriented rehabilitation approaches should be used [12-14].

Hybrid-Constrained Induced Movement Therapy (H-CIMT) [15], Constrained Induced Movement Therapy (CIMT) [16], Bimanual Intensive Movement Therapy (BIMT) [17], Hand and Arm Bimanual Intensive Therapy Including Lower Extremity (HABIT-ILE) [18], and Functional Intensive treatment (FitCare4U) [19] have all been proven to be effective intensive treatment methods for children with cerebral palsy. All these treatment options are based on motor learning and known to be effective on the level of activity rather than body structure and function domains of the International Classification of Functioning [20]. FitCare4U, an intensive therapy treatment for children and adolescents with disability, focuses on stimulating motor learning and neuroplasticity through intensive training of self-care and mobility to contribute to improved activity and participation. We hypothesized that this treatment method could contribute to improving participants' QOL and increasing their performance of the goals. Evaluations performed after the intensive treatment of upper extremities showed that the physical well-being domain of QOL in these children had improved [16].

\section{Materials and Methods}

\section{Participants}

Inclusion criteria were as follows: children and adolescents aged 12 to 18 years with any motor disability who have the abilities to stand or perform a standing transfer with or without support and to follow instructions. The FitCare4U program was applied and the outcome measures were used as in a usual care, after participants and parents signed informed consents.

\section{Procedures}

Intervention and assessments were part of the regular functional intensive treatment program in Adelante Centre of Pediatric Rehabilitation in the Netherlands. All participants and parent signed informed consents to use the outcome anonymous. The participants were assessed two weeks before start of the treatment - goals and quality of life-, directly after finishing the program- goals- and three months after the program had ended goals and quality of life. All participants and their parents completed KIDSCREEN questionnaires to evaluate the participants' QOL
[21], with scoring done separately for parents' and participants' responses. At the same time, participants' goals were determined by occupational therapists using the Canadian Occupational Performance Measure (COPM) [22]. Final COPM elements were set as participants' personal goals and became the starting point for the intervention.

\section{Intervention}

The FitCare4U approach is aimed to improve functionality and independency in self-care and mobility. The intervention is goaland needs based and included motor learning, active participation, and training in context. The participants were individually coached by members of a multidisciplinary team of pediatric physical and occupational therapists, sport teachers, nurses, social workers, psychologists and physicians. Each participant had one personal coach. All activities were performed in real-life context when possible. For example, sports activities were performed in the official sport accommodations. The program was planned to last 15 consecutive days in order to improve individuals' home participation, community participation, and peer relationships. Each day, six hours of therapy were practiced, so participants received a total of 90 hours of therapy. The participants stayed overnight during the whole intervention, attending schools in the mornings, while FitCare4U was performed in the afternoons and evenings.

Individual goals were practiced in 90-minute individual goaloriented training sessions, and goals were likewise considered and worked toward throughout each day in all relevant situations. Relevant goals were in the domain of daily activities, such as transfers, mobility, and independently sitting up, preparing sandwiches, dressing, and showering. On the weekends, activities started immediately after breakfast. The rest of the program consisted of physical and recreational group activities to improve participants' activity levels. After dinner, home based play and game activities were done. Participants were encouraged to perform at their maximum capacity during all activities; this included sitting on unsupported chairs even between activities and at break times, and walking tools were used minimally. They also actively participated in self-care activities, such as preparing food, using cutlery, cleaning and setting the dining table, and washing dishes. These activities were integrated into this program for daily skills training during activity-based therapy in the afternoon [19].

\section{Outcome Measures}

The primary outcomes in FitCare $4 \mathrm{U}$ related to QOL were measured using KIDSCREEN-52, which was developed for children and adolescents by the European Commission and is applicable to children and adolescents between the ages of 8 and 18. The dimensions of KIDSCREEN-52 include 52 items and 10 domains: physical well-being (5 items), psychological well-being (6 items), moods and emotions (7 items), self-perception (5 items), autonomy 
(5 items), parent relationships and home life (6 items), financial resources (3 items), social support and peer (6 items), school environment (6 items), and social acceptance/bullying (3 items). The psychometric properties of the KIDSCREEN were good, with Cronbach's alpha (the internal consistency) ranges from 0.77 to 0.89. The intraclass correlation coefficients (ICC) ranged from 0.56 to 0.77 . The KIDSCREEN scores were calculated for each of the ten domains and transformed into T-values, with a mean of 50 and standard deviation of 10 . Higher scores indicated better health as related to QOL and well-being [21,23]. Proxy reports of the KIDSCREEN assessment were completed by all parents, and self-reporting was completed by participants who did not have intellectual disability.

The Canadian Occupational Performance Measure (COPM) was used to measure secondary outcomes by first determining individual intervention goals for each participant, then stating changes in participants' self-perceptions of the performance of their needs and their satisfaction. The COPM includes a $20-30$ minutes interview about the children's daily routines. Participants or their parents identified problems that the children experience in performing daily living activities. The performance (ICC $=0.73$ ) and satisfaction (ICC $=0.83$ ) domains of the COPM have good reliability and validity [24]. Each activity was rated on a scale from 1 to 10 , with 1 meaning participants are not able to do something at all and 10 meaning they are able to do something extremely well, for perceived performance capacity and performance satisfaction. An improvement of two or more points has clinical significance. Participants collaborated with their families and occupational therapists to determine and prioritize participants' goals [22].

\section{Analyses}

Statistical analysis was performed using SPSS Statistics 21.0 (SPSS Inc., Chicago, IL, USA). Descriptive data have been presented as mean, standard deviation (SD), minimum, and maximum values. In the evaluation of the data, the normal distribution of the variables was examined by visual (histogram and probability graphs) and analytical methods (Kolmogorov-Smirnov / ShapiroWilk tests). In the analysis of the data, no normal distribution was shown; non-parametric statistics were used to detect the effects of the treatment. The Wilcoxon signed-rank test was used to detect the treatment effects based on the KIDSCREEN and COPM subtests. Spearman's rank-order test was used to determine correlations between the KIDSCREEN subtests of self and proxy report measures; the significance level was at $\mathrm{p}<0.05$.

\section{Results}

Thirty-one children between the ages of 12 and 18 participated in a FitCare4U intervention, and there were no adverse events. Before the camp, thirty-one caregivers completed proxy reports using KIDSCREEN and COPM assessments; nine out of thirtyone adolescent participants were unable to self-report using KIDSCREEN due to their intellectual impairment. Participants' mean ages were $14.13 \pm 2.306$ years.

\section{Primary Outcomes}

KIDSCREEN-52 was used to determine participants' QOL. This questionnaire was completed as a proxy-report and selfreport twice: before the intervention and three months after its completion. The physical well-being domain of the proxy report increased significantly after the intervention $(\mathrm{p}=0.01)$. The financial resources domain had the most missing data at the three-month follow-up assessment; only twenty-one out of thirtyone parents completed this domain (Tables 1 \& 2). Statistically significant increases were also observed in the school environment domain of the self-report follow-up assessment ( $p=0.006)$, with the bullying domain showing a similarly significant increase $(p=0.07)$. The proxy reports showed a significant increase in the domain of physical well-being $(p=0.01)$, but there were no significant differences in the other domains (Table 2). The correlation between self and proxy reported changes before and after the camp was examined; it was found that there was no statistically significant relationship between self and proxy reports (Table 3).

Table 1: Characteristics of Participants.

\begin{tabular}{|c|c|}
\hline Demographic Characteristics & Number (\%) \\
\hline \multicolumn{2}{|c|}{ Gender } \\
\hline Female & $14(45.2)$ \\
\hline Male & $17(54.8)$ \\
\hline \multicolumn{2}{|c|}{ Condition } \\
\hline Bilateral CP & $14(45.2)$ \\
\hline Unilateral CP & $4(12.9)$ \\
\hline Dyskinetic CP & $3(9.7)$ \\
\hline Hereditary Spastic CP & $3(9.7)$ \\
\hline Spina Bifida & $4(12.9)$ \\
\hline Muscular Dystrophy & $1(3.2)$ \\
\hline Hemispherectomy & $1(3.2)$ \\
\hline Achondroplasia & $1(3.2)$ \\
\hline
\end{tabular}

Table 2: Statistical analysis of KIDSCREEN between before intervention and after 3 months.

\begin{tabular}{|c|c|c|c|c|}
\hline Domains & \multicolumn{2}{|c|}{ Before Intervention } & \multicolumn{2}{c|}{ Follow-up Assessment } \\
\hline KIDSCREEN Self Report (n) & Mean (SD) & Min - Max Values (Median) & Mean (SD) & Min - Max Values (Median) \\
\hline $\begin{array}{c}\text { Physical Well-Being, self } \\
\text { report (n=22) }\end{array}$ & $47.083(9.682)$ & $32.69-73.20(47.082)$ & $50.596(11.227)$ & $34.65-73.20(49.627)$ \\
\hline $\begin{array}{c}\text { Psychological Well-Being, self } \\
\text { report }(\mathrm{n}=22)\end{array}$ & $55.711(8.847)$ & $39.91-68.49(54.495)$ & $56.629(8.630)$ & $39.91-68.49(57.603)$ \\
\hline
\end{tabular}




\begin{tabular}{|c|c|c|c|c|c|}
\hline $\begin{array}{l}\text { Mood and Emotions, self } \\
\quad \text { report }(\mathrm{n}=22)\end{array}$ & $50.173(11.411)$ & $33.58-70.91(47.151)$ & $53.484(12.403)$ & $31.42-70.91(52.682)$ & 0.098 \\
\hline $\begin{array}{l}\text { Self Perception, self report } \\
\qquad(\mathrm{n}=21)\end{array}$ & $53.799(11.554)$ & $37.85-69.78(52.186)$ & $57.493(11.206)$ & $39.21-69.78(57.7491)$ & 0.308 \\
\hline Autonomy, self report $(n=22)$ & $53.475(9.034)$ & $35.61-68.75(53.219)$ & $55.687(8.629)$ & $43.59-68.75(53.219)$ & 0.449 \\
\hline $\begin{array}{l}\text { Parent Relation Home Life, } \\
\text { self report }(\mathrm{n}=22)\end{array}$ & $57.123(8.821)$ & $39.69-65.87(58.528)$ & $58.916(7.388)$ & $45.72-65.87(58.528)$ & 0.344 \\
\hline $\begin{array}{l}\text { Financial Resources, self } \\
\text { report }(\mathrm{n}=18)\end{array}$ & $53.434(10.328)$ & $23.24-62.86(56.347)$ & $52.602(11.758)$ & $23.24-62.86(52.413)$ & 0.552 \\
\hline $\begin{array}{l}\text { Peers-Social Support, self } \\
\text { report }(\mathrm{n}=21)\end{array}$ & $53.953(10.797)$ & $35.44-71.46(54.933)$ & $56.581(10.992)$ & $36.81-71.46(58.136)$ & 0.338 \\
\hline $\begin{array}{l}\text { School Environment, self } \\
\text { report }(\mathrm{n}=21)\end{array}$ & $52.249(9.585)$ & $35.35-73.80(52.226)$ & $59.703(7.211)$ & $48.61-73.80(58.875)$ & $0.006^{* *}$ \\
\hline Bullying, self report $(n=22)$ & $46.203(11.100)$ & $29.13-58.85(48.071)$ & $51.235(9.988)$ & 33.13 - $58.85(58.847)$ & 0.07 \\
\hline \multicolumn{6}{|c|}{ KIDSCREEN Proxy Report (n) } \\
\hline $\begin{array}{l}\text { Physical Well-Being, proxy } \\
\text { report }(\mathrm{n}=26)\end{array}$ & $38.328(6.972)$ & $26.30-52.68(38.784)$ & $43.159(6.237)$ & $34.77-55.89(41.084)$ & $0.01^{* *}$ \\
\hline $\begin{array}{l}\text { Psychological Well-Being, } \\
\text { proxy report }(\mathrm{n}=25)\end{array}$ & $50.378(10.579)$ & $26.28-69.88(48.870)$ & $52.058(10.388)$ & $26.28-69.88(52.120)$ & 0.338 \\
\hline $\begin{array}{l}\text { Mood and Emotions, proxy } \\
\text { report }(\mathrm{n}=26)\end{array}$ & $46.763(12.050)$ & $28.43-70.82(46.123)$ & $47.709(11.420)$ & $20.72-70.82(49.928)$ & 0.587 \\
\hline $\begin{array}{l}\text { Self Perception, proxy report } \\
\qquad(n=26)\end{array}$ & $48.444(9.409)$ & $32.73-70.98(44.246)$ & $50.771(8.179)$ & $37.33-70.98(50.686)$ & 0.108 \\
\hline $\begin{array}{l}\text { Autonomy, proxy report } \\
\qquad(\mathrm{n}=26)\end{array}$ & $49.594(8.365)$ & $33.58-67.95(48.216)$ & $48.094(7.227)$ & $33.58-67.95(48.216)$ & 0.951 \\
\hline $\begin{array}{l}\text { Parent Relation Home Life, } \\
\text { proxy report }(\mathrm{n}=26)\end{array}$ & $55.406(8.443)$ & $36.17-69.22(55.129)$ & $55.019(8.296)$ & $40.20-69.22(55.129)$ & 0.781 \\
\hline $\begin{array}{l}\text { Financial Resources, proxy } \\
\text { report }(\mathrm{n}=20)\end{array}$ & $54.654(15.002)$ & $23.96-65.02(65.021)$ & $53.185(15.130)$ & $23.96-65.02(59.329)$ & 0.682 \\
\hline $\begin{array}{l}\text { Peers-Social Support, proxy } \\
\text { report }(\mathrm{n}=24)\end{array}$ & $41.544(15.300)$ & $8.28-73.08(42.458)$ & $42.472(14.103)$ & $8.28-73.08(40.518)$ & 0.56 \\
\hline $\begin{array}{l}\text { School Environment, proxy } \\
\text { report }(\mathrm{n}=25)\end{array}$ & $57.498(10.271)$ & $30.95-72.50(59.597)$ & $58.387(9.240)$ & $41.28-72.50(57.008)$ & 0.876 \\
\hline Bullying, proxy report $(\mathrm{n}=25)$ & $45.231(14.128)$ & $18.25-58.83(50.555)$ & $48.206(13.413)$ & $14.74-58.83(50.555)$ & 0.235 \\
\hline
\end{tabular}

${ }^{* *} \mathrm{p} \leq 0.01$

Min: minimum values of KIDSCREEN domains; max: maximum values of KIDSCREEN domains.

Table 3: Correlation analysis between before and 3 months later assessments of self and proxy report of quality of life.

\begin{tabular}{|c|c|c|}
\hline \multicolumn{3}{|c|}{ Differences Analysis between Self - Proxy } \\
\hline KIDSCREEN DOMAINS & Correlations & Significance \\
\hline Physical Well-Being & $r=-0.02$ & $\mathrm{p}=0.935$ \\
\hline Psychological Well-Being & $r=0.173$ & $\mathrm{p}=0.47$ \\
\hline Mood and Emotions & $r=-0.275$ & $\mathrm{p}=0.241$ \\
\hline Self Perception & $r=0.401$ & $\mathrm{p}=0.08$ \\
\hline Autonomy & $r=-0.178$ & $\mathrm{p}=0.453$ \\
\hline Parent Relation Home Life & $r=-0.285$ & $\mathrm{p}=0.223$ \\
\hline Financial Resources & $r=0.390$ & $\mathrm{p}=0.151$ \\
\hline Peers-Social Support & $\mathrm{r}=0.132$ & $\mathrm{p}=0.580$ \\
\hline School Environment & $r=0.181$ & $\mathrm{p}=0.457$ \\
\hline Bullying & $r=-0.087$ & $\mathrm{p}=0.723$ \\
\hline
\end{tabular}

\section{Secondary Outcomes}

Satisfaction and performance domains of COPM showed statistically significant increase after treatment for all participants $(\mathrm{p}=0.000 ; \mathrm{p}=0.000)$ (Table 4). 
Table 4: Statistical analysis of COPM between before intervention and after 3 months.

\begin{tabular}{|c|c|c|c|c|c|c|}
\hline \multirow[b]{2}{*}{ COPM } & \multirow{2}{*}{$\begin{array}{c}\text { N (Before/Follow- } \\
\text { up) }\end{array}$} & \multicolumn{2}{|c|}{ Before Intervention } & \multicolumn{2}{|c|}{ Follow-up Assessment } & \multirow[b]{2}{*}{$p$ values } \\
\hline & & Mean (SD) & $\begin{array}{l}\text { Min - Max Values } \\
\text { (Median) }\end{array}$ & Mean (SD) & $\begin{array}{l}\text { Min - Max Values } \\
\text { (Median) }\end{array}$ & \\
\hline Performance & $30 / 29$ & $3.233(1.101)$ & $1.00-5.59(3.00)$ & $6.810(1.109)$ & $4.70-8.70(7.00)$ & $0.0000\left(^{*}\right)$ \\
\hline Satisfaction & $30 / 29$ & 3.457 (1.217) & $1.00-6.00(3.10)$ & $6.997(1.095)$ & $4.70-8.80(7.3)$ & $0.0000\left(^{*}\right)$ \\
\hline
\end{tabular}

$\left.{ }^{*}\right) \mathrm{p} \leq 0.001$

Min: minimum values of COPM domains; max: maximum values of COPM domains.

\section{Discussion}

This study aimed to explore whether the QOL of children and adolescents with disabilities would improve after a functional intensive therapy program. It was found that most relevant outcomes from the KIDSCREEN assessment, including the domains of school environment (self-report) and physical well-being (proxyreport), increased. In addition, reported levels of performance and satisfaction, as assessed by the COPM, improved after the participants underwent the intensive therapy. As it is known, there is a strong correlation between the areas of functionality and physical well-being. Sakzewski, et al. found that intensive therapy had positive effects on the physical well-being domain in both proxy and self-reports [16]. Similarly, FitCare4U had positive effects on the physical well-being domain. An increase in physical well-being was expected because of the physical approach of Fitcare4U, which includes intensive outdoor activities, sports, and stimulation of active sitting, standing and mobility, as well as the intense practicing of self-care activity goals. These results were shown in the proxy report but not in the self-report, in agreement with the lack of correlation between the two reports.

Furthermore, the participants reported a significant increase in the school environment domain, indicating an improved quality of relationships between peers at school. In terms of child QOL, there is no definite conclusion about whether there exists a correlation between a caregiver/parent report and child report [25,26]. After the intervention, no statistically significant correlation was found between the increases in self and proxy reports of KIDSCREEN scores. This could have been caused in part by unequal sample sizes for self and proxy reports. Furthermore, QOL has a subjective construct, so different results might be obtained according to different perspectives; the QOL questionnaire scores of the parents and children reports were evaluated separately perspective in order to assess the QOL of the children with disability [25,27]. It has been shown that, three months after FitCare4U treatment, the satisfaction and performance areas of the COPM had significantly increased, indicating a transfer of the learned goals into daily life at home.

FitCare4U has a similar intensity and identical motor-learning concepts to other intensive treatment approaches, such as CIMT, BIMT, and HABIT-ILE [15-17,28], most of which showed similar results on the COPM. A limitation of the present study is that due to the three months period after the program many other aspects may affect participants' QOL. To identify impacts of FitCare4U more specifically, a control group should be included in a future study. As a result, it was concluded that FitCare $4 \mathrm{U}$ increased relevant domains of QOL and occupational performance of all disabled participants. Overall, it was concluded that FitCare4U increased relevant domains of QOL and occupational performance of the participants. The current study showed that participants had improved QOL and goal performances after undergoing FitCare4U therapy, therefore this treatment may be an appropriate intervention to improve the QOL of children and adolescents with disabilities.

\section{Acknowledgement}

We gratefully thank the participants, their families, the therapists, the health centre managers who helped with this study.

\section{Conflict of Interest}

The authors declare no conflict of interest.

\section{References}

1. The WHOQOL Group (1995) The World Health Organization quality of life assessment (WHOQOL): position paper from the World Health Organization. Social science \& medicine 41(10):1403-1409.

2. Bjornson K, Mc Laughlin J (2001) The measurement of health-related quality of life (HRQL) in children with cerebral palsy. European Journal of Neurology 8(S5):183-193.

3. Pollard EL, Lee PD (2003) Child well-being: A systematic review of the literature. Social Indicators Research 61(1): 59-78.

4. Omura J, Fuentes M, Bjornson K (2018) Participation in Daily Life: Influence on Quality of Life in Ambulatory Children with Cerebral Palsy. PM R 10(11): 1185-1191.

5. Power R, King C, Muhit M, Heanoy E, Galea C, et al. (2018) Health-related quality of life of children and adolescents with cerebral palsy in low- and middle-income countries: a systematic review. Dev Med Child Neurol 60(5): 469-479.

6. Bannink F, Idro R, Van Hove G (2018) Health related quality of life in children with spina bifida in Uganda. Disabil Health J 11(4): 650-654.

7. Harding L (2001) Children's quality of life assessments: a review of generic and health related quality of life measures completed by children and adolescents. Clinical Psychology \& Psychotherapy: An International Journal of Theory \& Practice 8(2): 79-96.

8. Alriksson Schmidt AI, Wallander J, Biasini F (2007) Quality of life and resilience in adolescents with a mobility disability. J Pediatr Psychol 32(3): 370-379. 
9. Chen H, Cohen P, Kasen S, Johnson JG, Berenson K, et al. (2006) Impact of adolescent mental disorders and physical illnesses on quality of life 17 years later. Archives of pediatrics \& adolescent medicine 160(1): 93-99.

10. Park SK, Yang DJ, Heo JW, Kim JH, Park SH, et al. (2016) Study on the quality of life of children with cerebral palsy. Journal of physical therapy science 28(11): 3145-3148.

11. Shelly A, Davis E, Waters E, Mackinnon A, Reddihough D, et al. (2008) The relationship between quality of life and functioning for children with cerebral palsy. Dev Med Child Neurol 50(3): 199-203.

12. Arpino C, Vescio MF, De Luca A, Curatolo P (2010) Efficacy of intensive versus nonintensive physiotherapy in children with cerebral palsy: a meta-analysis. International Journal of Rehabilitation Research 33(2): 165-171.

13. Stiller C, Marcoux BC, Olson RE (2003) The effect of conductive education, intensive therapy, and special education services on motor skills in children with cerebral palsy. Physical \& Occupational Therapy in Pediatrics 23(3): 31-50.

14. Verschuren O, Ketelaar M, Gorter JW, Helders PJ, Uiterwaal CS, et al (2007) Exercise training program in children and adolescents with cerebral palsy: a randomized controlled trial. Archives of pediatrics \& adolescent medicine 161(11): 1075-1081.

15. Brauers L, Geijen MM, Speth LA, Rameckers EA (2017) Does intensive upper limb treatment modality Hybrid Constrained Induced Movement Therapy (H-CIMT) improve grip and pinch strength or fatigability of the affected hand? J Pediatr Rehabil Med 10(1): 11-17.

16. Sakzewski L, Carlon S, Shields N, Ziviani J, Ware RS, et al. (2012) Impact of intensive upper limb rehabilitation on quality of life: a randomized trial in children with unilateral cerebral palsy. Dev Med Child Neurol 54(5): 415-423.

17. Plasschaert VFP, Vriezekolk JE, Aarts PBM, Geurts ACH, Van den Ende CHM (2019) Interventions to improve upper limb function for children with bilateral cerebral palsy: a systematic review. Dev Med Child Neurol 61(8): 899-907.

18. Bleyenheuft Y, Ebner Karestinos D, Surana B, Paradis J, Sidiropoulos A et al. (2017) Intensive upper- and lower-extremity training for children with bilateral cerebral palsy: a quasi-randomized trial. Dev Med Child Neurol 59(6): 625-633

\section{ISSN: 2574-1241}

DOI: 10.26717/BJSTR.2020.31.005091

Buse Busra Sanli. Biomed J Sci \& Tech Res

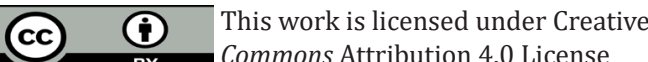

Submission Link: https://biomedres.us/submit-manuscript.php
19. Roelofsma R, Rameckers E (2017) The Effect of a Functional Intensive Intervention Program on Self-Care in Children with Cerebral Palsy: A Case Study. Int J Brain Disord Treat 3: 021.

20. Sakzewski L, Gordon A, Eliasson AC (2014) The state of the evidence for intensive upper limb therapy approaches for children with unilateral cerebral palsy. Journal of Child Neurology 29(8): 1077-1090.

21. Ravens Sieberer U, Gosch A, Rajmil L, Erhart M, Bruil J, et al. (2005) KIDSCREEN-52 quality-of-life measure for children and adolescents. Expert review of pharmacoeconomics \& outcomes research 5(3): 353364.

22. Mc Coll MA, Paterson M, Davies D, Doubt L, Law M (2000) Validity and community utility of the Canadian Occupational Performance Measure. Canadian Journal of Occupational Therapy 67(1): 22-30.

23. Ravens Sieberer U, Gosch A, Rajmil L, Erhart M, Bruil J, et al. (2008) The KIDSCREEN-52 quality of life measure for children and adolescents: psychometric results from a cross-cultural survey in 13 European countries. Value in health 11(4): 645-658.

24. Cusick A, Lannin NA, Lowe K (2007) Adapting the Canadian Occupational Performance Measure for use in a paediatric clinical trial. Disability and rehabilitation 29(10): 761-766.

25. Bray N, Noyes J, Harris N, Edwards RT (2017) Measuring the healthrelated quality of life of children with impaired mobility: examining correlation and agreement between children and parent proxies. BMC Res Notes 10: 377.

26. Varni JW, Burwinkle TM, Sherman SA, Hanna K, Berrin SJ, et al. (2005) Health-related quality of life of children and adolescents with cerebral palsy: hearing the voices of the children. Developmental Medicine and Child Neurology 47(9): 592-597.

27. Leidy NK, Revicki DA, Genesté B (1999) Recommendations for evaluating the validity of quality of life claims for labeling and promotion. Value in Health 2(2): 113-127.

28. Eliasson AC, Bonnier B, Krumlinde Sundholm L (2003) Clinical experience of constraint induced movement therapy in adolescents with hemiplegic cerebral palsy-a day camp model. Developmental medicine and child neurology 45(5): 357-359.

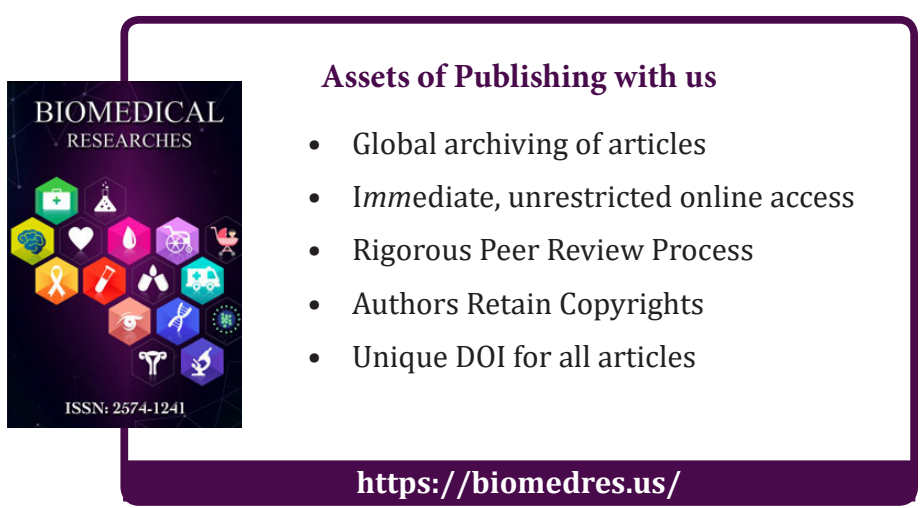

